\title{
Unusual Development of
}

latrogenic Complex, Mixed

Biliary and Duodenal Fistulas

Complicating Roux-en-Y Antrectomy

for Stenotic Peptic Disease of the

Supraampullary Duodenum

Requiring Whipple Procedure:

An Uncommon Clinical Dilemma

\author{
Francesco A. Polistina ${ }^{a} \quad$ Giorgio Costantin ${ }^{a}$
}

Alessandro Settin ${ }^{a}$ Franco Lumachi ${ }^{b}$

Giovanni Ambrosino ${ }^{b}$

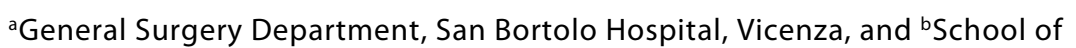
General Surgery, University of Padua, Padua, Italy

\section{Key Words}

Duodenal fistulas · Biliary fistulas · Pancreatoduodenectomy · Gastric surgery complications

\begin{abstract}
Complex fistulas of the duodenum and biliary tree are severe complications of gastric surgery. The association of duodenal and major biliary fistulas occurs rarely and is a major challenge for treatment. They may occur during virtually any kind of operation, but they are more frequent in cases complicated by the presence of difficult duodenal ulcers or cancer, with a mortality rate of up to $35 \%$. Options for treatment are many and range from simple drainage to extended resections and difficult reconstructions. Conservative treatment is the choice for well-drained fistulas, but some cases require reoperation. Very little is known about reoperation techniques and technical selection of the right patients. We present the case of a complex iatrogenic duodenal and biliary fistula. A 42-year-old Caucasian man with a diagnosis of postoperative peritonitis had been operated on 3 days earlier; an antrectomy with a Roux-en-Y reconstruction for stenotic peptic disease was performed. Conservative treatment was attempted with mixed results. Two more operations were required to achieve a definitive resolution of the fistula and related local complications. The decision was made to perform a
\end{abstract}




\begin{tabular}{r|l|l|l}
$\begin{array}{r}\text { Case Reports in } \\
\text { Gastruanteriology }\end{array}$ & $\begin{array}{l}\text { Case Rep Gastroenterol 2010;4:476-483 } \\
\text { DOI: 10.1159/000322027 }\end{array}$ & $\begin{array}{l}\text { Published online: } \\
\text { October 23, 2010 }\end{array}$ & $\begin{array}{l}\text { O 2010 S. Karger AG, Basel } \\
\text { ISSN 1662-0631 } \\
\text { www.karger.com/crg }\end{array}$ \\
\hline
\end{tabular}

pancreatoduodenectomy with subsequent reconstruction on a double jejunal loop. The patient did well and was discharged on postoperative day 17. In our experience pancreaticoduodenectomy may be an effective treatment of refractory and complex iatrogenic fistulas involving both the duodenum and the biliary tree.

\section{Introduction}

Duodenal fistula is an infrequent but life-threatening complication of gastric surgery, with an incidence estimated to be 3-8\% in several series [1]. General agreement has been reached to use conservative treatment of well-drained fistulas [2]; however, in some instances the complexity and the appearance of peritonitis or the long-lasting persistence of fistulas require reoperation [2]. Very little is known about reoperation technique; reoperation may include a wide range of techniques varying from simple drainage to patching or extensive demolition with subsequent reconstruction which carries a high morbidity and mortality. We present the case of a complex iatrogenic duodenal and biliary fistula managed during a 4-month period and requiring pancreatoduodenectomy for definitive treatment.

\section{Case Report}

On October 28, 2005, a 42-year-old Caucasian man was referred to our hepatobiliopancreatic surgery division from a secondary center with a diagnosis of postoperative peritonitis. The patient had no history of other significant disease except for a chronic duodenal peptic ulcer with stenotic evolution. He had been operated on 3 days earlier with a distal gastric resection and a Roux-en-Y reconstruction for a peptic stricture of the proximal duodenum. The operation was started using a laparoscopic approach, but it was converted to laparotomy as a result of unspecified technical difficulties. On postoperative (p.o.) day 3 , the patient experienced acute abdomen and was reoperated on by the same surgeon, who described the presence of a large periduodenal fluid collection with evidence of local infection. During this second operation, drainage of the peripancreatic space and placement of a T-tube in the biliary tree were performed.

On arrival to our center, the patient exhibited septic shock condition; a complete abdominal computed tomography (CT) scan (fig. 1) revealed a wide intraabdominal abscess. Percutaneous fluoroscopic-guided repositioning of the drains placed during the previous operations was performed. Fistulography showed a complex fistula in the periduodenal area (fig. 2). Total parenteral nutrition (TPN) was started immediately, together with octreotide administration at a dose of $0.5 \mathrm{mg} /$ day via subcutaneous injection 2 times a day. Antibiotics were given on the basis of amoxicillin-clavulanate $2 \mathrm{~g}$ every $6 \mathrm{~h}$ intravenously. The patient's condition improved, and his septic status was completely resolved on p.o. day 8 . Approximately $900 \mathrm{ml} / 24 \mathrm{~h}$ of amylase-rich biliary fluid came from the drainages. After a water-soluble contrast upper gastrointestinal examination showing good patency of the gastrojejunal anastomosis, a mixed TPN and oral nutrition regimen was started. With the consistent reduction of fluid from the drainages to less than $100 \mathrm{ml} /$ day of amylase-rich fluid, the patient was discharged on p.o. day 20 (p.o. day 23 from the first operation) with the drains (a periduodenal silicone-elastomer $28 \mathrm{~F}$ tube and a T-tube in the biliary tree) left in situ and with oral food intake, and followed on a daily basis in the clinic.

On p.o. day 34 (p.o. day 37 from the first operation), the patient presented complaining of fever and severe abdominal pain. On physical examination a marked abdominal tenderness in the upper right quadrant and mesogastric area was evident. He was readmitted to the hospital. Abdominal CT showed a recurrent abscess in the periduodenal area, and a further fistulography showed the previously known fistula with displacement of both the periduodenal tube and the distal branch of the T-tube. The patient underwent surgical reexploration, at which time we noticed the presence of a $3 \times 3 \mathrm{~cm}$ hole in the lateral aspect of the wall of the second part of the duodenum. After a cholecystectomy, a catheter was inserted 
and a cholangiogram was obtained; it showed 3 fistulas in the biliary tree (lower choledochus, medium choledochus, and common hepatic duct), but no duodenal obstruction was found. A complete toilette was performed, and the drains and the biliary drainage were repositioned. The option to perform a hepaticojejunal biliary diversion was excluded because of extensive inflammation in the peripancreatic area. The patient's general condition improved dramatically after the operation, but the drains persisted with an average output of $800 \mathrm{ml} /$ day of amylase-rich biliary fluid requiring continuous replacement to avoid electrolyte disturbances. On reduction of the drainage output to less than $100 \mathrm{ml} /$ day of still amylase-rich clear fluid, a control abdominal ultrasonogram showed no collections in the periduodenal area. All drains were removed except for the periduodenal one and the T-tube. The drain output decreased to $50 \mathrm{ml} / 24 \mathrm{~h}$ of clear fluid with a low amylase concentration. The patient was discharged on p.o. day 22 (p.o. day 56 from the second operation and p.o. day 59 from the first operation) and returned to the clinic for follow-up on a daily basis.

Two weeks after discharge (p.o. day 36 from the third operation), the patient was readmitted with jaundice, tremors, chills, fever, and upper right abdominal quadrant pain. On physical examination, he showed pain on palpation of the right upper quadrant and enlargement of the liver. Contrast-enhanced CT scan revealed no fluid collections in the periduodenal area, and bile culture showed mixed infection from Enterococcus organisms and methicillin-resistant Staphylococcus aureus. Cholangitis was diagnosed, and antibiotic therapy was started with ampicillin and vancomycin, with complete remission on day 9. Oral food intake was restarted on post-readmission day 5. He was discharged again on p.o. day 45 from the third operation, and returned to the clinic for follow-up with both the T-tube and the periduodenal tube still in place, draining less than $100 \mathrm{ml} /$ day of clear fluid with an average amylase concentration of 2,000 U/l; no bile had ever appeared in the fluid collected from the periduodenal drain.

On February 14, 2006 (p.o. day 113 from the first operation, p.o. day 110 from the second operation, and p.o. day 76 from the third operation), the patient presented complaining of a sudden worsening of his clinical condition: fever and abdominal pain appeared together with severe leukocytosis, and abdominal examination showed frank diffuse tenderness. After urgent readmission, contrast-enhanced $\mathrm{CT}$ of the abdomen showed bowel distension with widespread abdominal fluid collection and signs of necrosis in the right colon wall; there was no recurrent abscess in the periduodenal area (fig. 3 ). An emergent reoperation was then decided on. Intraoperative findings were as follows: the right colonic wall showed superficial necrotic areas and no evident perforation, and there was right colonic artery thrombosis with no pulse in the marginal artery until the right colonic flexure. The wall of the second duodenal portion was completely missing, and the ampulla of Vater appeared in the surgeon's view. Perioperative cholangiogram showed the persistence of the lower choledochus fistula and complete leakage from the duodenal wall; no leakage was noted from the previous upper biliary fistulas. An extended right colectomy was performed, associated with a pancreaticoduodenectomy and reconstruction of the biliary and pancreatic anastomoses on two separate defunctionalized jejunal loops.

The postoperative period was characterized by the onset of a low-output pancreatic fistula. The patient was discharged on p.o. day 17 from the fourth operation. The pancreatic fistula had healed spontaneously on p.o. day 32 from the fourth operation, and the drains were definitively removed on p.o. day 35. At 58 months, the patient is doing well; however, he requires pancreatic enzyme replacement and ferrous and folate supplementation as a result of malabsorption. His body mass index is $28 \mathrm{~kg} / \mathrm{m}^{2}$, and he leads a normal life.

\section{Discussion}

Complex fistulas of the duodenum and biliary tree are a rare, life-threatening complication of gastric surgery. The association between duodenal and major biliary fistulas occurs rarely, but is a serious challenge for treatment. Such fistulas may complicate virtually any operation in the peripancreatic area, but are more likely to occur in the presence of complex duodenal ulcers or cancer [1]. A high mortality rate of up to $35 \%$ has been described in association with such a complication $[2,3]$. Death may occur as a result of either infectious or systemic complications, mainly electrolyte imbalance. Skin changes at the external fistula orifice may exacerbate the patient's discomfort. 


\begin{tabular}{r|l|l|l}
$\begin{array}{r}\text { Case Reports in } \\
\text { Gastruenterology }\end{array}$ & $\begin{array}{l}\text { Case Rep Gastroenterol 2010;4:476-483 } \\
\text { DOI: 10.1159/000322027 }\end{array}$ & $\begin{array}{l}\text { Published online: } \\
\text { October 23, 2010 }\end{array}$ & $\begin{array}{l}\text { O 2010 S. Karger AG, Basel } \\
\text { ISSN 1662-0631 } \\
\text { www.karger.com/crg }\end{array}$ \\
\hline
\end{tabular}

Postoperative fistulas are associated with a lengthening of hospitalization, leading to an increased exposure to hospital infections.

In an elegant review by Falconi and Pederzoli [1], the single association of duodenal fistulas with distal gastric resection was reported to be $0-6 \%$, with a $0-4 \%$ overall mortality rate, whereas an approximately $10 \%$ mortality rate is found with biliary complex fistulas [4]. In the described case we faced a double situation: a lateral high-output duodenal fistula and a complex biliary fistula having at least three leakage points on the biliary tract. Moreover, the previous Roux-en-Y gastrojejunostomy had made it impossible either to treat at least the biliary fistula by endoscopic stenting or to obtain a reliable diagnostic study according to current literature suggestions [5-7]. We decided to apply a conservative strategy, and fluoroscopy was used to reposition the drains that were already in place, obtaining a good external drainage of the fistulas and achieving a good clinical response.

A critical point in managing upper gastrointestinal fistulas is the patient's nutritional status. Malnutrition is often an additional cause for delayed healing as it acts by at least three different mechanisms: lack of food intake, loss of protein-and energy-rich fluid in fistula discharge, and hypercatabolism associated with sepsis [8]; therefore, the maintenance of a good nutritional status is mandatory [9-11]. Once we obtained resolution of the sepsis, we applied a mixed regimen of TPN plus oral nutrition; oral nutrition was permitted by the presence of a well-performing gastrojejunostomy, but concomitant TPN was necessary to keep electrolytes balanced. Oral food intake was administered as a water-soluble mixture of simple fats, glutamine, arginine, fish oils, nucleosides, nucleotides, trace elements, and vitamins as provided by our nutritional service. We did not notice any increase in the fistula output at the reprise of oral intake as reported by some authors $[9,12-14]$. We routinely use octreotide in treating gastrointestinal fistulas, usually at the recommended dose of $0.5 \mathrm{mg}$ given subcutaneously in two administrations. The rationale for use of octreotide is that by reducing overall output volume and enzyme secretion, the risk of local tissue injury by the latter is reduced, even in the absence of strong evidence of the usefulness of octreotide [15-19]. Our patient showed an initial significant decrease in fistula output with apparent resolution within 5 weeks. At 5 weeks he was readmitted with an abdominal abscess requiring reoperation.

At surgical exploration we found dislocation of both the T-tube and the peripancreatic drains, a lateral duodenal fistula with a maximal diameter of $3 \mathrm{~cm}$, and a periduodenal abscess. Cholecystectomy was performed, and a cholangiogram was obtained through a transcystic approach, confirming three lesions in the lower and middle choledochus and in the common hepatic bile duct; the decision was made to separately drain the three biliary lesions and the peripancreatic spaces. Postoperatively the inflammatory state resolved, but the fistula persisted with a high output. Nutrition was restarted as before, together with octreotide. Once again the patient improved with the persistence of the fistula.

The characteristics of the duodenal fistula suggested to us that it had never healed spontaneously: it was lateral and greater than $2 \mathrm{~cm}$, with unhealthy tissues surrounding it [1]. We also knew that the correct timing for definitive treatment should be delayed by at least 6 weeks after resolution of the systemic inflammatory response [14, 20,21]. While we were considering the ultimate reoperation for definitive fistula treatment, the patient 


\begin{tabular}{r|l|l|l}
$\begin{array}{r}\text { Case Reports in } \\
\text { Gastruenterology }\end{array}$ & $\begin{array}{l}\text { Case Rep Gastroenterol 2010;4:476-483 } \\
\text { DOI: 10.1159/000322027 }\end{array}$ & $\begin{array}{l}\text { Published online: } \\
\text { October 23, 2010 }\end{array}$ & $\begin{array}{l}\text { O 2010 S. Karger AG, Basel } \\
\text { ISSN 1662-0631 } \\
\text { www.karger.com/crg }\end{array}$ \\
\hline
\end{tabular}

experienced a right colonic acute ischemia requiring further urgent laparotomy. At operation we did not find significant inflammation at the duodenal and periduodenal tissues. The decision was made to treat the fistula and colon at once.

Options for repair of duodenal fistulas are many, with the choice depending on the surgeon's decision at the time of operation. In our case we had to consider the extension and complexity of the biliary damage and the high risk of recurrence if we repaired the duodenum. A hepaticojejunal anastomosis was appropriate for treatment of biliary fistulas, but the issue was how to deal with such a damaged duodenum. Applying a serosal jejunal patch seemed to have limited chances of success, even though this procedure has been well described in a number of papers [21,22], and duodenectomy with primary reimplantation of the ampulla of Vater $[23,24]$ did not appear to have a greater chance of cure because of the complex situation that would have also required a hepaticojejunostomy. Similar to several reported cases [25-28], the decision was made to perform a pancreaticoduodenectomy, and reconstruction was performed on two separate defunctionalized jejunal loops for each bile duct and the pancreatic stump, which was anastomosed in an end-to-end invaginated fashion. The operation was successfully carried out, and the patient recovered. A low-output pancreatic fistula developed postoperatively, but it resolved spontaneously within 32 days. The patient is doing well and has achieved a normal lifestyle under ferrous and folate supplementation as a result of malabsorption and pancreatic enzyme supplementation owing to steatorrhea.

\section{Conclusion}

We can confirm that in our fortunate and limited experience, pancreaticoduodenectomy may be an effective solution in the treatment of refractory and complex fistulas involving both the duodenum and the biliary tree. Operation must be carried out with a delay of at least 6 weeks from the drainage, and associated acute bowel disease seems not to contraindicate the procedure when there are no abscesses in or near the pancreaticoduodenal area. The rarity of such cases limits the possibility of a wider experience; therefore, we suggest that only experienced surgeons in highly specialized centers should perform this technique.

\section{Acknowledgements}

The authors are grateful to Miss Paola Benoffi for her assistance with image adjustments. 


\begin{tabular}{l|l|l|l}
$\begin{array}{r}\text { Case Reports in } \\
\text { Gastroenteriology }\end{array}$ & $\begin{array}{l}\text { Case Rep Gastroenterol 2010;4:476-483 } \\
\text { DOl: 10.1159/000322027 }\end{array}$ & $\begin{array}{l}\text { Published online: } \\
\text { October 23, 2010 }\end{array}$ & $\begin{array}{l}\text { O 2010 S. Karger AG, Basel } \\
\text { ISSN 162--0631 } \\
\text { www.karger.com/crg }\end{array}$ \\
\hline
\end{tabular}

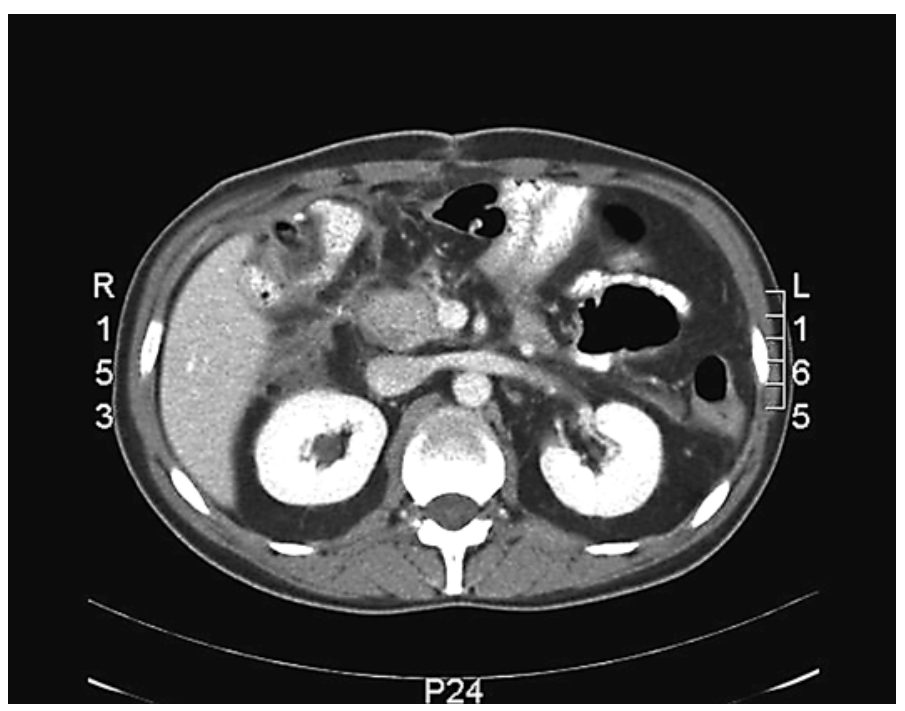

Fig. 1. Abdominal CT scan showing a wide paraduodenal fluid collection. The images were acquired upon the patient's admission.

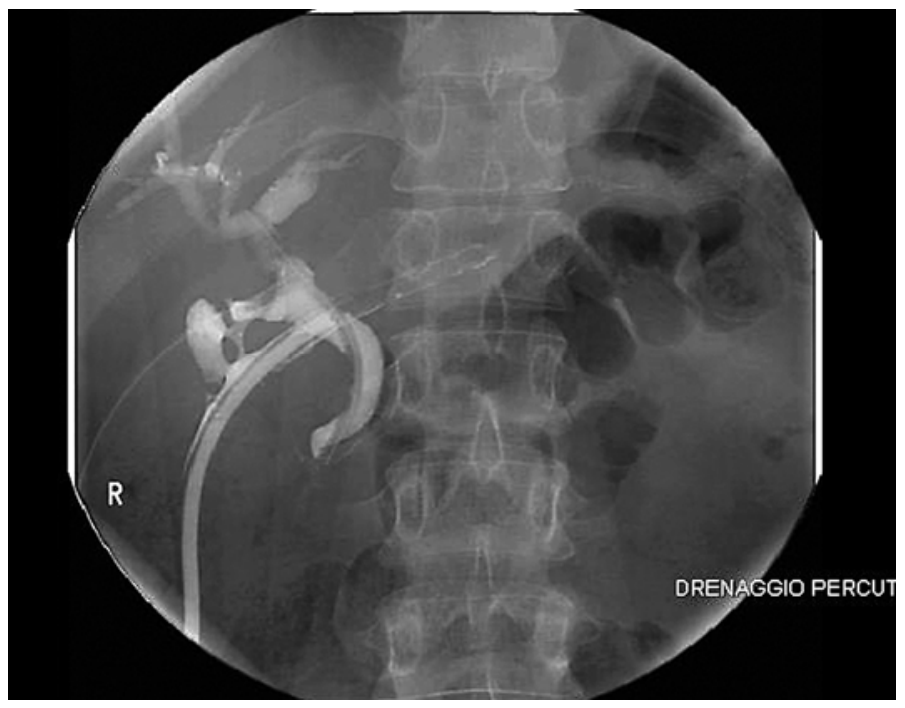

Fig. 2. Fistulography showing the presence of a wide damage on the coledochal lateral wall. 


\begin{tabular}{r|l|l|l}
$\begin{array}{r}\text { Case Reports in } \\
\text { Gastruanteriology }\end{array}$ & $\begin{array}{l}\text { Case Rep Gastroenterol 2010;4:476-483 } \\
\text { DOI: 10.1159/000322027 }\end{array}$ & $\begin{array}{l}\text { Published online: } \\
\text { October 23, 2010 }\end{array}$ & $\begin{array}{l}\text { O 2010 S. Karger AG, Basel } \\
\text { ISSN 1662-0631 } \\
\text { www.karger.com/crg }\end{array}$ \\
\hline
\end{tabular}

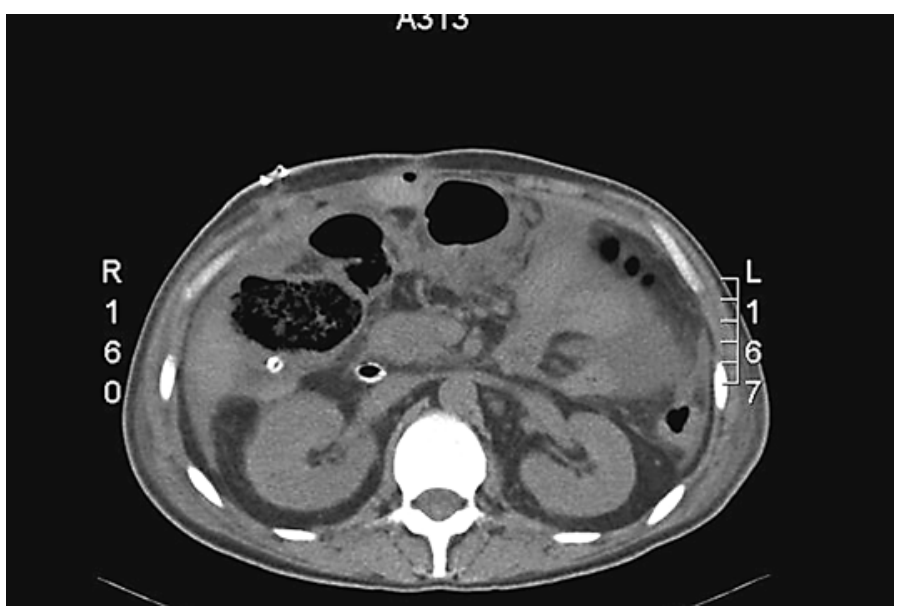

Fig. 3. Non-contrast-enhanced abdominal CT scan showing necrosis of the right colonic wall and diffuse but not periduodenal abdominal fluid collections.

\section{References}

1 Falconi M, Pederzoli P: The relevance of gastrointestinal fistulae in clinical practice: a review. Gut 2001;49 (suppl IV):iv2-iv10.

2 González Pinto I, González EM: Optimising the treatment of upper gastrointestinal fistulae. Gut 2001;49 (suppl IV):iv22-iv31.

3 Dudrick SJ, Maharaj AR, McKelvey AA: Artificial nutritional support in patients with gastrointestinal fistulas. World J Surg 1999;23:570-576.

-4 Davids PH, Rauws EA, Tytgat GN, Huibregtse K: Postoperative bile leakage: endoscopic management. Gut 1992;33:1118-1122.

5 Agarwal N, Sharma BC, Garg S, Kumar R, Sarin SK: Endoscopic management of postoperative bile leaks. Hepatobiliary Pancreat Dis Int 2006;5:273-277.

6 Thomas HA: Radiologic investigation and treatment of gastrointestinal fistulas. Surg Clin North Am 1996;76:1081-1094.

77 Foley MJ, Ghahremani GG, Rogers LF: Reappraisal of contrast media used to detect upper gastrointestinal perforations: comparison of ionic water-soluble media with barium sulfate. Radiology 1982;144:231-237.

-8 Fischer JE: The pathophysiology of enterocutaneous fistulas. World J Surg 1983;7:446-450.

9 Meguid MM, Campos ACL: Nutritional management of patients with gastrointestinal fistulas. Surg Clin North Am 1996;76:1035-1080.

10 Dárdai E, Pirityi S, Nagy L: Parenteral and enteral nutrition and the enterocutaneous fistula treatment. Factors influencing the outcome of treatment. Acta Chir Hung 1991;32:305-318.

11 Verma GR, Kaman L, Singh G, Singh R, Behera A, Bose SM: External duodenal fistula following closure of duodenal perforation. Indian J Gastroenterol 2006;25:16-19.

-12 Traverso LW, Abou-Zamzam AM, Maxwell DS, Lacy SM, Tompkins RK: The effect of total parenteral nutrition or elemental diet on pancreatic proteolytic activity and ultrastructure. JPEN J Parenter Enteral Nutr 1981;5:496-500.

13 Bivins BA, Bell RM, Rapp RP, Toedebush WH: Pancreatic exocrine response to parenteral nutrition. JPEN J Parenter Enteral Nutr 1984;8:34-36.

14 Draus JM Jr, Huss SA, Harty NJ, Cheadle WG, Larson GM: Enterocutaneous fistula: are treatments improving? Surgery 2006;140:570-578.

15 Nubiola-Calonge P, Badía JM, Sancho J, Gil MJ, Segura M, Sitges Serra A: Blind evaluation of the effect of octreotide (SMS 201-995), a somatostatin analogue, on small bowel fistula output. Lancet 1987;2:672-674. 
16 Hernandez Aranda JC, Gallo Chico G, Flores Ramirez LA, Avalos Huante R, Magos Vazquez FJ, Ramirez Barba EJ: Treatment of enterocutaneous fistulae with or without octreotide and parenteral nutrition. Nutr Hosp 1996;11:226-229.

17 Ahmad RR, Fawzy SY: Enterocutaneous fistula. Causes and management. Saudi Med J 2007;28:1408-1413.

18 Alivizatos V, Felekis D, Zorbalas A: Evaluation of the effectiveness of octreotide in the conservative treatment of postoperative percutaneous fistulas. Hepatogastroenterology 2002;49:1010-1012.

-19 Sancho JJ, di Costanzo J, Nubiola P, Larrad A, Beguiristain A, Roqueta F, Franch G, Oliva A, Gubern JM, Sitges Serra A: Randomized double blind placebo-controlled trial of early octreotide in patients with postoperative enterocutaneous fistula. Br J Surg 1995;82:638-641.

20 Rolandelli R, Roslyn JJ: Surgical management and treatment of sepsis associated with gastrointestinal fistulas. Surg Clin North Am 1996;76:1111-1122.

21 Malangoni MA, Madura JA, Jesseph JE: Management of lateral duodenal fistulas: a study of fourteen cases. Surgery 1982;90:645-651.

22 Kalyani A, Teoh CM, Sukumar N: I jejunal patch repair of a duodenal perforation. Med J Malaysia 2005;60:237-238.

23 Young JS, Goco I, Pennelli T: Duodenectomy and reimplantation of the ampulla of Vater for megaduodenum. Am Surg 1993;59:685-688.

24 Bardini R, Segalina A, Asolati M: Disconnection of the ampulla of Vater; a new technique for reconstruction. Hepatogastroenterology 1998;45:1479-1481.

25 Kluger Y, Hadad R, Soffer D, Aladgem D, Klausner JY: Whipple operation in trauma. Harefuah 1997;132: 366-368.

26 Asensio JA, Petrone P, Roldán G, Kuncir E, Demetriades D: Pancreaticoduodenectomy: a rare procedure for the management of complex pancreaticoduodenal injuries. J Am Coll Surg 2003;197:937-942.

-27 Krige JE, Beningfield SJ, Nicol AJ, Navsaria P: The management of complex pancreatic injuries. S Afr J Surg 2005;43:92-102.

28 Sekino Y, Kobayashi A, Takagi S, Miwa S, Miyagawa S: Successful treatment for combined pancreatoduodenal injury by a second stage pancreatojejunostomy following pancreatoduodenectomy. Hepatogastroenterology 2004;51:1674-1675. 